\title{
Saúde na Escola: Reflexões a partir das vivências de estudantes de fisioterapia.
}

\section{School Health: Reflections from the experiences of physical therapy students.}

\section{Salud Escolar: Reflexiones desde las experiencias de estudiantes de fisioterapia.}

\author{
Elísio Alves Pereira NETO ${ }^{1}$ \\ Josielma Juvito FERREIRA ${ }^{2}$ \\ Kaísa Thomaz Cavalcante e SILVA ${ }^{3}$ \\ Mayara Gabriel Lima de MENDONÇA ${ }^{4}$ \\ Renata Newman Leite Cardoso dos SANTOS ${ }^{5}$ \\ Kátia Suely Queiroz Silva RIBEIRO ${ }^{6}$
}

RESUMO: O Programa Saúde na Escola pretende integrar e articular de forma permanente a educação e a saúde no Brasil, favorecendo para a melhoria da qualidade de vida da população. O propósito é auxiliar uma formação integral dos estudantes através da realização de ações de promoção, prevenção e atenção à saúde juntamente com profissionais da saúde, da educação, como também de estudantes da área. $\mathrm{O}$ objetivo deste artigo, portanto, é compartilhar as vivências dos acadêmicos de Fisioterapia da UFPB no Programa Saúde na Escola e a importância dessa prática na formação profissional. $\mathrm{O}$ estudo foi realizado em uma escola da periferia da cidade de João Pessoa - PB, onde quatro estagiários do oitavo período do curso de Fisioterapia desenvolveram durante dois meses atividades de educação na escola para, aproximadamente, 30 crianças. A experiência vivenciada foi sistematizada por meio do método de cinco tempos. Em seguida, os discursos obtidos foram analisados por meio da análise temática. Os estagiários apontaram que a 1 Universidade Federal da Paraíba. Graduando em Fisioterapia. E-mail: elisioapn@hotmail.com

2 Universidade Federal da Paraíba. Graduando em Fisioterapia. E-mail: josy_ferreira16@hotmail.com

3 Universidade Federal da Paraíba. Graduando em Fisioterapia. E-mail: kaisa-thomaz@bol.com.br

4 Universidade Federal da Paraíba. Graduando em Fisioterapia. E-mail: mayaragabriel.fisio@hotmail.com

5 Universidade Federal da Paraíba. Fisioterapeuta, Mestre em Modelos de decisão e Saúde e Doutoranda em

Modelos de Decisão e Saúde UFPB. Professora Substituta do departamento de Fisioterapia - UFPB. E-mail: renatanewman@hotmail.com

6 Universidade Federal da Paraíba. Fisioterapeuta, Docente do departamento de Fisioterapia, Doutora em Educação. E-mail: katiaqsribeiro@yahoo.com.br 
vivência no programa contribuiu para o crescimento acadêmico e permitiu que eles observassem a importância de uma atuação conjunta com outros setores e também permitiu que percebessem como uma atuação no nível da atenção básica dentro do ambiente escolar pode ser transformadora, não apenas para as crianças que participaram das atividades, mas também de todos ao seu redor, sobretudo por ter sido pautada na educação popular.

Palavras-chave: Saúde Escolar. Fisioterapia. Atenção Primária à saúde.

ABSTRACT: The School Health Program aims to integrate and coordinate permanently education and health in Brazil, favoring to improve the population's quality of life. The purpose is to assist an integral formation of students by conducting promotion, prevention and health care along with health professionals, education, as well as students of the area. The purpose of this article, therefore, is to share the experiences of UFPB physiotherapy students in the School Health Program and the importance of this practice in vocational training. The study was conducted in a school on the outskirts of the city of João Pessoa - PB, where four trainees of the eighth Physiotherapy course period developed for two months education activities at school for about 30 children. The experiment was experienced systemized through five days method. Then the speeches were analyzed through thematic analysis. Trainees indicated that the experience in the program contributed to the academic growth and allowed them to observe the importance of joint action with other sectors and also allowed realized as a performance at the level of primary care within the school environment can be transformative, not only for children who participated in the activities, but also all around, especially for having been based on popular education.

Keywords: School Health. Physical Therapy. Primary Health Care.

RESUMEN: El Programa de Salud de la Escuela tiene como objetivo integrar y coordinar de forma permanente la educación y la salud en Brasil, a favor de mejorar la calidad de vida de la población. El propósito es ayudar a la formación integral de los estudiantes mediante la realización de promoción, prevención y atención de la salud, junto con profesionales de la salud, la educación, así como los estudiantes de la zona. El propósito de este artículo, por lo tanto, es compartir las experiencias de los estudiantes de fisioterapia UFPb en el Programa de Salud de la Escuela y la importancia de esta práctica en la formación profesional. El estudio se realizó en una escuela en las afueras de la ciudad de João Pessoa - PB, donde cuatro aprendices del periodo del curso de Fisioterapia octava desarrollado durante dos meses las actividades de educación en la escuela durante unos 30 niños. El experimento se experimentó sistematizado a través del método de cinco días. A continuación, los discursos fueron analizados mediante análisis temático. Los alumnos indicaron que la experiencia en el programa contribuyó al crecimiento académico y les permitió observar la importancia de la acción conjunta con otros sectores y también permitió que se dio cuenta de que una actuación a nivel de la atención primaria en el entorno escolar puede ser transformador, no sólo para los niños que participaron en las actividades, sino también por todas partes, sobre todo por haber sido basado en la educación popular.

Palabras clave: Salud Escolar. Fisioterapia. Atención Primaria de Salud. 


\section{INTRODUÇÃO}

Diversas estratégias e programas têm sido elaborados e implementados no sentido de alcançar os objetivos definidos para a atenção primária em saúde, visando o desenvolvimento de ações de promoção e prevenção em saúde, além das ações tradicionalmente realizadas para tratamento e reabilitação. Nesse contexto o Ministério da Saúde propôs o Programa Saúde na Escola (PSE)

O PSE depende de uma ação conjunta de vários setores que atuem em sintonia com os princípios doutrinários do Sistema Único de Saúde (SUS) ${ }^{1}$. Instituído em 2007, este programa visa a integração e articulação permanente da educação e da saúde, proporcionando melhoria da qualidade de vida da população brasileira. Tem como objetivo contribuir para a formação integral dos estudantes por meio de ações de promoção, prevenção e atenção à saúde, com vistas ao enfrentamento das vulnerabilidades que comprometem o pleno desenvolvimento de crianças e jovens da rede pública de ensino. O público beneficiário do PSE são os estudantes da Educação Básica, gestores e profissionais de educação e saúde, comunidade escolar e, de forma mais amplificada, estudantes da Rede Federal de Educação Profissional e Tecnológica e da Educação de Jovens e Adultos (EJA2²,3.

Nesse contexto, o curso de graduação em Fisioterapia da Universidade Federal da Paraíba (UFPB) proporciona aos seus acadêmicos a vivência em Saúde na Escola no oitavo semestre do curso, como parte das atividades do Estágio em Saúde Coletiva. Durante essa vivência, os estagiários têm a oportunidade de conhecer e realizar na prática atividades de prevenção e promoção à saúde dentro das escolas da comunidade onde esse estágio é realizado.

Baseando-se nos princípios do SUS, nas diretrizes do PSE e nos princípios da educação popular em saúde, os acadêmicos realizam ações que visem à prevenção e promoção da saúde, sempre de maneira integral e buscando impactar positivamente os indivíduos que participam da ação.

Deste modo, o presente artigo tem como objetivo compartilhar as vivências de acadêmicos de Fisioterapia da UFPB na atuação na perspectiva do PSE, a importância dessa prática na formação profissional, além de descrever as atividades que foram realizadas na escola em questão.

\section{METODOLOGIA}

Para a realização do presente artigo foi utilizada a técnica de sistematização de experiências na qual há uma interpretação crítica de experiências, e que, por meio de ordenação e reconstrução, produz conhecimentos a partir da experiência vivida, utilizando o método de cinco tempos ${ }^{4}$.

A análise da experiência vivenciada se deu a partir dos relatos de quatro acadêmicos de Fisioterapia que participaram das atividades do PSE, além de registros fotográficos das experiências vividas. Os discursos foram coletados após o término do estágio quando cada estagiário realizou um registro escrito, descrevendo sua experiência no Estágio em Saúde Coletiva. 
O método de cinco tempos afirma que todo processo de sistematização consiste de cinco etapas ou cinco tempos. O primeiro tempo caracteriza-se por ter como ponto de partida o fato de que para sistematizar uma experiência se faz necessário ter participado da experiência e registrar a mesma, dessa forma apenas os estudantes de Fisioterapia foram responsáveis pela sistematização.

Num segundo momento foram determinadas e respondidas as perguntas iniciais que direcionam o processo de sistematização como, por exemplo, definir o objetivo de compartilhar as experiências vividas pelos graduandos de Fisioterapia na atuação no PSE e selecionar quais aspectos fundamentais e centrais da experiência e o que foi percebido e apreendido por esses acadêmicos após a experiência.

Para a reconstrução do processo vivido os graduandos se reuniram para, juntamente com o auxílio dos registros fotográficos, ordenar, classificar e recuperar todas as informações relativas à experiência vivenciada. Consequentemente, isso tornou possível a realização da quarta etapa na qual ocorreu a reflexão propriamente dita. Foram realizados debates para que se chegassem a repostas a algumas perguntas como, por exemplo, "O que aconteceu?", "Por que determinado fato aconteceu? ", "Qual a importância dessa experiência?”, entre outras. Procedeu-se a uma análise temática dos discursos oriundos das respostas a estes questionamentos, a qual, de acordo com $\operatorname{Bardin}^{5}$ (p.201) é "eficaz na condição de se aplicar a discursos diretos e simples".

Finalmente, após todas as questões serem exaustivamente discutidas, os alunos formularam conclusões, determinaram o ponto de chegada e elaboraram o presente manuscrito para comunicar o que foi vivido e apreendido.

\section{Caracterização dos cenários de prática}

A experiência sistematizada nesse estudo foi desenvolvida em uma escola municipal de um bairro da periferia da cidade de João Pessoa, Paraíba.

A escola contava com alunos do primeiro ao nono ano do ensino fundamental. A turma na qual foram realizadas as atividades educativas foi a do $6^{\circ}$ ano $\mathrm{B}$, que possuía aproximadamente 30 alunos com idades entre 10 e 12 anos, esta turma foi escolhida mediante sugestão da direção da escola para que as atividades dos acadêmicos fossem desenvolvidas.

\section{Atividades desenvolvidas}

O período de realização das atividades foi entre os meses de outubro e dezembro de 2014 . As atividades foram planejadas juntamente com os docentes da disciplina de Estágio em Saúde Coletiva e a direção da escola onde foram desenvolvidas as atividades, sendo a temática definida com base nas demandas apresentadas pelos dirigentes escolares. A temática escolhida para ser abordada junto aos alunos do $6^{\circ}$ ano B foi a "Inclusão Social das pessoas com Deficiência". Essa temática foi trabalhada na Escola ao longo do ano de 2014. 
As ações desenvolvidas pelos acadêmicos de Fisioterapia duraram seis semanas e a cada semana havia um encontro de aproximadamente 50 minutos a 1 hora entre os acadêmicos e a turma em questão para discutir o tema proposto. Foram priorizadas atividades teórico-práticas que aliassem a teoria com a aplicabilidade no dia a dia das crianças acerca das discussões realizadas.

Os três primeiros encontros foram planejados para que houvesse a introdução ao tema proposto utilizando-se de recursos como filmes curtas-metragens, momentos de discussão e reflexão entre os alunos e os estagiários de Fisioterapia. Foram realizadas, também, dinâmicas relacionadas com a inclusão social da pessoa com deficiência, atividades que estimulassem o trabalho em grupo e socialização com os colegas e explanações teóricas pertinentes ao tema proposto.

Ao término desta primeira etapa, foi programada uma atividade de culminância, momento em que os alunos do $6^{\circ}$ ano $\mathrm{B}$ apresentaram para toda a escola o que foi discutido durante esse período, como forma de compartilhar os aprendizados com os demais estudantes.

A atividade de culminância foi realizada no ginásio da escola e os alunos encenaram uma peça teatral e apresentaram uma paródia musical que tratavam sobre a importância da inclusão da pessoa com deficiência no âmbito escolar.

\section{RESULTADOS E DISCUSSÃO}

\section{Saúde na escola: vivências, reflexões e aprendizados dos acadêmicos de Fisioterapia}

O desenvolvimento de atividades do PSE permitiu aos acadêmicos uma troca de experiências com horizontalização entre os saberes científicos e populares, além de incentivar a corresponsabilidade para a construção do conceito de saúde. A ação orientada pela educação popular em saúde requer abertura, disponibilidade para ouvir o outro, nivelar na relação interpessoal e na ação educativa em si, pois, o ato participativo é humanizador 6 . Isso implica dizer que todo conhecimento é inacabado e que sempre pode ser complementado por outros saberes.

O profissional de saúde participa constantemente de um processo educacional, independente de estar atuando em uma sala de aula ou não. Tanto o ato de tratar como o ato de educar representam um encontro, uma negociação, um ato intersubjetivo, que visa à internalização de um pensar e agir por parte dos sujeitos implicados nesta relação ${ }^{7}$ e para que sejam atingidos os objetivos desejados, essa internalização de conhecimentos deve ser mediada por palavras e também por atitudes.

A educação em saúde deve provocar conflitos nos indivíduos, criando oportunidade da pessoa pensar e repensar a sua cultura, e ele próprio transformar sua realidade ${ }^{8}$. Nesse sentido, os temas trabalhados devem condizer com a realidade vivenciada pelos indivíduos, despertando o interesse para a obtenção de melhores condições de vida e de saúde.

A partir das informações discutidas e construídas em sala de aula, os estudantes participantes 
dessa experiência, tornaram-se disseminadores das mesmas e as levaram para o ambiente familiar e a comunidade em que vive, segundo o discurso de um dos acadêmicos:

Durante a apresentação dos slides, os alunos já começavam a interagir e mostravam certa intimidade com o assunto, chegando a citar e comentar os tipos de deficiência e a falar sobre o papel de cada um como cidadão. Os saberes (cientifico e popular) iam se complementando e a conversa se tornava fluida. Estar ali, exercendo mais o papel de professor do que de fisioterapeuta, aumentou nossa responsabilidade, tendo como principais objetivos, incentivar a participação desses alunos no processo de construção para melhores condições de saúde de toda aquela população e promover mudanças de ações e de atitudes, principalmente com relação às pessoas com deficiência, e não apenas transmitir informações. Sabíamos que aquelas crianças sairiam da sala de aula com conceitos e formações diferentes sobre o assunto e os levariam para além do ambiente escolar, e isso nos fez enxergar o que seria a educação em saúde (Estagiário I).

A escola onde foram realizadas as atividades é referência para pessoas com deficiência naquela região da cidade. Possui uma estrutura diferenciada, com rampas de acesso a cadeirantes, banheiros acessíveis, além de contar com uma sala de Atendimento Educacional Especializado e profissionais capacitados, que lançam mão de instrumentos psicopedagógicos específicos para facilitar a aprendizagem daqueles alunos que requerem maior atenção. Estudantes com deficiência de outras escolas são encaminhados para esse atendimento. O discurso de um acadêmico de Fisioterapia evidencia a importância desse serviço na escola:

Fui surpreendida pela diversidade de brinquedos, jogos, cadeiras adaptadas, instrumentos disponíveis para facilitar a aprendizagem dos alunos que apresentam alguma deficiência, seja ela qual for. Nunca tinha parado para refletir sobre a educação, a melhor forma de incluir tais alunos e tornar o ensino acessivel e prazeroso. Aproximei-me mais desse mundo tão amplo e diverso, fui informada de como são aplicadas as provas e de que os alunos têm um horário marcado com a pedagoga em um turno diferente do qual assistem aula, para um melhor aproveitamento do ensino. Percebi que a inclusão é realmente possivel, basta ter empenho dos pais e dos profissionais de educação. Além disso, apesar de ser uma escola da prefeitura não deixa a desejar, como muitos pensam, muito pelo contrário, dá muito mais suporte a esses alunos do que muitas escolas particulares (Estagiário II).

Foi perceptível que os alunos daquela escola gostaram e se empenharam no desenvolvimento das dinâmicas propostas, foram estimulados a construir uma base reflexiva e propositiva sobre o processo da inclusão na escola. Eles mesmos se viram como agentes transformadores da sociedade, conforme o discurso do estagiário:

Ao final da culminância apresentada pelos alunos, me alegrei ao ver o rostinho de empolgação $e$ motivação dos mesmos. Estavam dispostos a expor todo o conhecimento e aprendizados adquiridos nas vivências nas últimas semanas. Foi algo renovador, tanto para nós acadêmicos como para os alunos que se surpreenderam com sua capacidade de atuar, falar, abordar um tema ainda coberto com ignorância e preconceito. Viram que podiam e são um agente transformador do mundo, e o melhor que tudo foi resultante de um processo construtivo de algumas semanas. É possível trabalhar a educação e saúde na escola, basta abraçar a causa e fazer com que todos se empenhem e queiram fazer a mudança (Estagiário III).

Tempus, actas de saúde colet, Brasília, 10(1), 231-239, mar, 2016. 
A escola é um dos alicerces da educação, da cidadania e da formação de uma nação. É por meio dela que a criança inicia sua educação, sua integração e inclusão social, seus relacionamentos e seus potenciais, ou seja, relações complexas que se estendem por toda a vida ${ }^{9}$. Nesse contexto vemos que ela é o espaço essencial para o desenvolvimento do conhecimento e para a propagação dos saberes perante a comunidade, contribuindo para uma melhoria na qualidade de vida em toda sociedade, seja direta ou indiretamente.

O tratamento dado às pessoas com deficiência tem mudado ao longo dos séculos, onde sempre existiu uma constante histórica: a marginalização ${ }^{10}$. Termos como idiotas, imbecis, excepcionais, dementes, amentes, deformados foram utilizados para definir a pessoa que tem alguma deficiência ao longo da história da humanidade e que, infelizmente, ainda estão presentes na contemporaneidade. O preconceito supõe um saber prévio e independente a escuta interpessoal, inviabilizando qualquer possibilidade de diálogo com o outro em sua inteireza e contribui para a negação da alteridade da pessoa que é submetida ao ato de preconceito $^{11}$.

Trabalhar a inclusão na escola não é uma tarefa simples, visto que a sociedade adota tais costumes e estes são passados para as novas gerações. A escola carrega este desafio de adotar e executar mudanças, mostrar novas visões aos alunos e profissionais, para que assim os mesmos saibam refletir e agir perante uma sociedade baseada em estereótipos e modismos.

É errôneo pensar que a atuação do profissional de saúde se limita as paredes de um consultório ou um hospital, é um pensamento fora do contexto da realidade que exclui a própria sociedade e seus costumes. Interferir no início do desenvolvimento infantil é agir como promoção e prevenção da saúde, pois a mesma influenciará nos hábitos de vida futuros reduzindo assim conflitos, problemas em saúde, evitando patologias e aumentando a qualidade de vida. Como evidencia um dos estagiários:

Acredito ser de suma importância a realização de atividades na escola para a contribuição do saber profissional e construção do fisioterapeuta, como agente formador em saúde. Apesar de ser uma profissão que classicamente é conhecida pela reabilitação, não se pode deixar as outras áreas de atuação de lado. É importante que o fisioterapeuta esteja inserido nesse contexto de educação para sempre agregar conhecimentos, mas também saber ouvir e aprender com a população em questão. (Estagiário IV)

A inserção do fisioterapeuta nos serviços de atenção primária à saúde é um processo em construção, associado, principalmente a criação da profissão, rotulando o fisioterapeuta como reabilitador, voltando-se apenas para uma pequena parte de seu objeto de trabalho, que é tratar a doença e suas sequelas. Essa lógica de conceitualização, durante muito tempo, excluiu da rede básica os serviços de fisioterapia, acarretando uma grande dificuldade de acesso da população a esse serviço e impedindo o profissional de atuar na atenção primária ${ }^{12}$.

Acredita-se que esses fatores contribuam com as dificuldades de o profissional desenhar o novo modelo de atenção centrado principalmente na prevenção de doenças e na promoção da 
saúde. Portanto, mais do que recuperar e curar as pessoas é preciso criar condições necessárias para que a saúde se desenvolva. O fisioterapeuta tem importante contribuição a dar por ser um profissional que se dedica ao estudo e a investigação do movimento humano, das funções corporais, do desenvolvimento das potencialidades, atividades laborativas e da vida diária, entre outros, e tudo isso privilegiando a utilização de recursos da natureza e do próprio corpo humano ${ }^{13}$. Experiências como essa no PSE durante a formação acadêmica revelam-se de suma importância para ampliar as possibilidades de atuação do fisioterapeuta.

\section{CONSIDERAÇÕES FINAIS}

Diante das situações vivenciadas, analisadas e sistematizadas podemos ver que o PSE é bastante relevante tanto para o processo de formação profissional, ultrapassando a prática baseada apenas na área biológica e que se limita a entender o processo saúde-doença, quanto para a sociedade. Desenvolver um trabalho que permite maior aproximação com a comunidade, desperta a responsabilidade dos profissionais fisioterapeutas que atuam numa perspectiva ampliada de cuidado em saúde, tendo como missão promover esse bem tão valioso ao ser humano.

Aescola é um ambiente que fornece ao aluno contato com os mais diversos tipos de conhecimentos, onde cada um pode ir construindo-o à sua maneira. O PSE é uma maneira prática e construtiva de processo educacional, gerando efeitos e ações na comunidade, como conscientização dos problemas sociais, tomadas de soluções e valorização dos direitos e deveres como cidadão.

Temas como deficiência e inclusão social representam uma realidade bem próxima aos alunos que convivem diariamente com pessoas com deficiência. Essa proximidade possibilitou que as atividades desenvolvidas no PSE e abordadas neste artigo fossem construídas com receptividade, facilidade e êxito. Nesse sentido, evidenciou-se que a orientação da educação popular foi fundamental para o sucesso da experiência, uma vez que contribuiu para a construção horizontal do conhecimento.

\section{FONTES DE FINANCIAMENTO}

Não houve fontes de financiamento para a pesquisa.

\section{REFERÊNCIAS BIBLIOGRÁFICAS}

1. Silva AM, Almeida VL, Oliveria F, Franco TLB. Classificação do grau de risco de famílias na estratégia saúde da família. Rev APS. 2014;17(1):111 - 115.

2. Brasil. Decreto ${ }^{0}$ 6.286, 5 de Dezembro de 2007. Institui o Programa Saúde na Escola PSE, e dá outras providências. Diário Oficial, Brasília, DF, 6 de Dezembro de 2007. 
3. Floss M, Miranda Júnior AD, Teixeira TP. Liga de educação em saúde : reflexões a partir das vivências dos estudantes de medicina. Rev APS. 2014;17(1):116 - 119.

4. Holliday OJ. Para sistematizar experiências. 2 ed. Brasília: MMA, 2006.

5. Bardin L. Análise de Conteúdo. São Paulo: Edições 70, 2011.

6. Alvin NAT, Ferreira MA. Perspectiva problematizadora da educação popular em saúde e a enfermagem. Revista Texto \& Contexto Enfermagem. 2007;16(2):315-319.

7. Garcia MAA. Saber, agir e educar: o ensino-aprendizagem em serviços de Saúde. Interface Comunic, Saúde, Educ. 2001;5(8):89-100.

8. Oliveira HM, Gonçalves MJF. Educação em saúde: uma experiência transformadora. Revista Bras Enferm. 2004;57(6):16-3.

9. Liberal EF. Acidentes e danos com escolares: incidência, causas e consequências. Jornal de Pediatria . 2005;81(5):155-163.

10. Diaz ALA. História de las Deficiências. Madrid: Escuela Libre Editorial, 1995.

11. Bartholo R. Alteridade e Preconceito. São Carlos: EDUFSCAR, 2007.

12. Ribeiro KSQ. A atuação da fisioterapia na atenção primária à saúde. Fisiot Brasil. 2002;3(5):311-318.

13. Barros FBM. (Org.). O fisioterapeuta na saúde da população: atuação transformadora. Rio de Janeiro: Fisiobrasil, 2002.

Artigo apresentado em 12-05-15

Artigo aprovado em 15-01-16

Artigo publicado no sistema em 30-03-16 